\title{
ANALISIS PELAKSANAAN PAJAK BUMI DAN BANGUNAN PERDESAAN DAN PERKOTAAN PADA KOTA TOMOHON
}

\author{
Yesika Claudia Lengkong ${ }^{1}$, Grace B. Nangoi ${ }^{2}$, Tressje Runtu ${ }^{3}$ \\ 1,2,3 Jurusan Akuntansi, Fakultas Ekonomi dan Bisnis, Universitas Sam Ratulangi, Jl.Kampus Bahu, Manado, \\ 95115, Indonesia
}

Email : yesikaclaudia11@gmail.com

\begin{abstract}
This scientist was done at the office of the city's government of Tomohon was especially done with Regional Financial (Income, Financial, and Regional Assets) the city of Tomohon located in the North Sulawesi Province. While the implementation time of this research is from April 2018 to September 2018. The purpose of this study was to determine the implementation of registration, data collection, assessment, determination, payment, service, collection and supervision in PBB-P2 collection by the Office of Revenue, Management of Finance and Regional Property in Tomohon. The population in this study are several individuals who are the source of data collection. The research sample is the Tomohon City Regional Revenue Service Officer who deals with Regional Taxes and Levies. In this study, the author uses descriptive methods. Data collection techniques used in this study are Field Research and Library Research. Data analysis was carried out by presenting the results obtained from research conducted to study and discuss the management of Land Taxes and Rural and Urban Buildings at the Tomohon City Regional Revenue Service. The conclusions of this study are: The implementation of PBB-P2 in the Department of Revenue, Management of Finance and Regional Property in Tomohon has followed the existing rules procedures and is in accordance with UN legislation, namely Law No. 12 of 2009 concerning Land and Building Taxes.
\end{abstract}

Keywords :Tax assessments of the earth and the country and urban buildings.

\section{PENDAHULUAN}

Indonesia merupakan suatu Negara yang berkembang saat ini, dan pembangunannya mencakup berbagai bidang. Untuk mencapai tujuan negara maka PBB-P2 diahlikannya menjadi Pajak Daerah yang pada mulanya PBB-P2 dilakukang oleh pemerintah pusat. Setelah dikeluarkan UU no. 28 tahun 2009 maka pengelolaan PBB-P2 dialihkan menjadi pajak daerah. Dari pemerintah pusat kepada pemerintah daerah harus melakukan persiapan yang sangat matang dalam mencapainya suatu proses pemindahan wewenang atas suatu pemungutan PBB-P2. Untuk menerima pengalihan pemungutan PBB-P2 maka pemerintah telah bekerja sama dengan Menteri Keuangan nomor 15/PMK.07/07/2014 mengenai adanya tanggung jawab dan tugas pemerintah daerah untuk menerima pengalihan pemungutan ini.

Yang harus dipersiapkan oleh pemerintah untuk pemungutan ini adalah dengan kerja sama dengan pihak yang terkait, standar operasi prosedur, peraturan kepala daerah, peraturan daerah, sumber daya manusia, sarana dan prasana, struktur organisasi dan tata kerja dan pembukaan rekening pada bank yang telah ditentukan. Selain itu juga dijelaskan bahwa tahun pengalihan pemungutan PBB-P2 ke pemerintah daerah dilaksanakan paling lambat pada tahun 2014. Sejak awal tahun 2014 masing masing pemerintah kabupaten/kota sudah melaksanakan pemungutan PBB-P2. Salah satu pemerintah kabupaten/kota yang sudah melaksanakan pemungutan PBB-P2 adalah pemerintah kota Tomohon. Pemungutan PBB-P2 ini baru dilaksanakan pada tanggal 1 Januari 2014. 


\section{TINJAUAN PUSTAKA}

Definisi Akutansi Pajak. Supriyanto (2015:2) menyatakan bahwa akuntansi adalah suatu proses pencatatan, pengihtisaran dan rangkuman data laporan keuangan.

Definisi Pajak. Soemitro (2013) mengemukakan bahwa iuaran pajak digunakan untuk membiayai pengeluaran umum (iuran rakyat kepada kas negara).

\section{Pengertian PBB}

Pajak PBB sebagai Pajak Daerah. Pajak Bumi dan Bangunan merupakan pajak nasional. Meskipun termasuk pajak nasional, tetapi penerimaan terbesar dan bahkan hamper semua pemasukanya adalah dikembalikan ke daerah.

Penetapan Tarif Pajak. Berdasarkan data yang telah dikumpulkan petugas akan ditentukan besarnya biaya kena pajak suatu objek pajak atau besarnya pajak terhutang. Besarnya pajak terhutang yang harus di bayar oleh wajib pajak juga tergantung kepada klasifikasi objek pajak yang dimilikinya.

Ditjen Perimbangan Keuangan 2014. Ditulis berdasarkan Dirtjen Perimbangan Keuangan tentang "Pendoman Umum Pengelolaan Pajak Bumi Dan Bangunan Perdesaan dan Perkotaan" yang dimulai dari Pendaftaran, Pendataan, Penilaian, Penetapan, Pembayaran, Penagihan, Teknologi Informasi, Pelayanan PBB-P2, dan Motoring Realisasi Penerimaan PBB-P2 (Ditjen Perimbangan Keuangan, 2014: 19-72).

\section{METODE PENELITIAN}

Jenis Penelitian. Sesuai dengan apa yang penelitian sampaikan maka penelitian ini memakai data kualitatif yang dalam bentuk uraian kata.

Tempat Dan Waktu Penelitian. Lokasi peneliti ini di kantor Keuangan Daerah Kota Tomohon. Dengan waktu penelitian dimulai pada bulan April - Oktober 2018.

\section{Jenis, Sumber Dan Metode Pengumpulan Data}

Jenis Data. Ada beberapa jenis jenis data yang dikemukakan oleh Kuncoro (2013:) yaitu :

1. Data kualitatif. Data Kualitatif adalah suatu data yang dilihat/menggambarkan suatu kondisi yang sebenarnya terjadi.

2. Data kuantitatif. Sedangkan data kuantitatif yaitu data yang berhubungan dengan jumlah/angka.

Sumber Data. Ada dua sumber data yaitu :

1. Data primer. Merupakan data yang di olah langsung dari sumbernya.

2. Data sekunder. Data ini dilakukan melalui media perantara atau tidak secara langsung.

Metode Pengumpulan Data. Penelitian ini menggunakan teknik dan prosedur yang sebagai berikut :

1. Teknik wawancara, untuk mengumpulkan data harus dengan melakukan Tanya jawab.

2. Obeservasi lapangan, teknik yang dilakukan dengan cara mengamati mengenai masalah peneliti.

3. Dokumentasi, teknik yang mengumpulkan secara langsung dokumen dan catatan-catatan digunakan oleh pemerintah.

4. Studi kepustakaan dilakukan untuk mengumpulkan permasalahan peneliti.

Metode Dan Proses Analisis. Analisis data untuk menyederhanakan data peneliti lebih mudah di mengerti dan pahami. Metode deskriptif untuk menganalisis dan menginterpretasikan data. 


\section{HASIL ANALISIS DAN PEMBAHASAN}

\subsection{Hasil Penelitian}

Kota Tomohon terletak pada $01^{\circ} 18^{\prime} 51^{\prime \prime}$ lintang utara dan $124^{\circ} 49^{\prime} 40^{\prime \prime}$ bujur timur. Luas Kota Tomohon adalah 147,21 km² dan berada pada ketinggian 400-1500 m dpl dengan suhu pada kisaran $18^{\circ} \mathrm{c}-30^{\circ} \mathrm{c}$. Kota Tomohon dapat dicapai dengan menggunakan sarana transportasi darat dari Kota Manado sebagai ibu kota provinsi dengan jarak tempuh sekitar 25 $\mathrm{km}$, dari Bandara Internasional Sam Ratulangi berjarak $34 \mathrm{~km}$, sedangkan dari Pelabuhan Bitung menuju Tomohon sekitar $60 \mathrm{~km}$. Sesuai dengan hasil survey lapangan maka didapatkan hasil penelitian mulai dari pendaftaran, pendataan, penilaian, penetapan, pembayaran, penagihan, pelayanan dan monitoring semua sesuai dengan prosedur SOP Dirjen Perimbangan Keuangan dan hanya terdapat perbedaan SOP di Teknik Informasi.

\subsection{Pembahasan}

1. Pendaftaran yang dilakukan ini telah sesuai dengan SOP yaitu dimulai dari WP melakukan pendaftaran objek, mengisi formulir dan kerja sama dengan instusi yang terkait.

2. Pendataan. Mulai dari persiapan, tahap pekerjaan lapangan dan tahap pekerjaan kantor ini telah sesuai dengan SOP.

3. Penilaian ini telah mengikuti prosedur SOP dimulai dari jenis objek pajak dan metode pendekatan penilaian.

4. Penetapan ini telah sesuai dengan SOP yang ditetapkan mulai penetapan NJOP, SPPT, SKPD dan Surat Ketetapan Pajak Daerah Lebih Bayar (SKPDLB).

5. Pembayaran ini telah mengikuti prosedur SOP yang ditetapkan.

6. Penagihan telah sesuai dengan prosedur SOP.

7. Teknologi Informasi tidak sesuai karena Aplikasi Sistem Informasi yang dipakai adalah SIPOLI.

8. Pelayanan ini telah mengikuti aturan SOP dan juga pelayanannya dinilai memuaskan.

9. Memonitoring ini telah mengikuti aturan SOP.

Kendala-kendala dan solusi yang dihadapi :

1. Dari wajib pajak melakukan pemutahiran data ke perangkat desa dan perangkat desa membuat laporan kepada Keuangan daerah Kota Tomohon menjadi perekaman data yang sebenarnya perangkat desa juga harus membuat laporan pemutahiran data. Solusi yang diambil adalah dengan penghapusan data sebelumnya.

2. Wajib pajak mengajukan keberatan mengenai tingginya pembayaran. Solusinya adalah pengurangan keberatan atas tingginya pembayaran dan setelah itu dihitungnya penghitungan pajak dengan melalui prosedur tertentu.

3. Wajib pajak sudah memiliki 1 SPPT dan 1 surat buku dan 1 sertifikat dan harus salah satu yang dimutasikan dan jika wajib pajak memiliki tunggakan selama 5 tahun tidak bisa dilakukan pemutahiran karena wajib pajak harus melunasi tunggakan selama 5 tahun. Solusi yang diambil diterbitkan surat teguran kepada wajib pajak dan melakukan penyitaan yang belum melunasi/membayar pajak terutangnya.

4. Wajib pajak yang menjual tanah harus melakukan pemutahiran tetapi yang terdapat pada survey lapangan wajib pajak yang menjual tanah melakukan perekaman data, dan wajib pajak yang membeli tanah mengetahui mengenai adanya permasalahan mengenai tunggakan pembayaran yang harus dibayarkan. Solusi yang sudah dilakukan dengan pemberian lewat media masa dan mengadakan penyuluhan melalui perangkat desa agar para wajib pajak penunggak segera melunasinnya.

5. Adanya pemekaran wilayah dibeberapa lokasi menyebabkan adanya perubahan data objek dan wajib pajak solusinya diperlukan pembaharuan data. 


\section{KESIMPULAN DAN SARAN}

\subsection{Kesimpulan}

Berdasarkan hasil penelitian yang telah dilakukan kesimpulan sebagai berikut :

1. Pelaksanaan PBB-P2 pada Keuangan Daerah di Kota Tomohon telah mengikuti prosedur dan setiap aturan yang ada.

2. Ada berbagai kendala-kendala dan solusi yang dihadapi di Keuangan Daerah Kota Tomohon salah satunya dari wajib pajak melakukan pemutahiran data ke perangkat desa dan perangkat desa membuat laporan kepada Keuangan daerah Kota Tomohon menjadi perekaman data yang sebenarnya perangkat desa juga harus membuat laporan pemutahiran data. Solusi yang diambil adalah dengan penghapusan data sebelumnya.

\subsection{Saran}

1. Semoga bisa dapat meningkatkan kinerja dan menambah kualitas pelayanan kepada masyarakat agar bisa meningkatkan pajak penerimaan.

2. Meningkatkan kesadaran dan pemahaman kepada masyarakat dan agar masyarakat lebih mengetahui dan memahami tentang peraturan daerah terlebih mengenai PBB-P2

3. Sekiranya lebih tingkatkan pengawasannya agar lebih efektif dan efesien menjalankan tugas.

\section{DAFTAR PUSTAKA}

Alni, Arya Riska. 2013. Analsis Partisipasi Masyarakat Dalam Membayar Pajak Bumi Dan Bangunan Di Kecamatan Rambah Hilir. Skripsi. Universitas Islam Negeri Sultan Syarif Kasim Riau Baru. Pekan Baru.

Burton, Rhicard. 2014. Kajian Aktual Perpajakan. Jakarta: Salemba Empat.

Chichi Juriko, Nangoi Grace, Pangerapan Sonny. 2017. Analisis efektivitas dan kontribusi pajak bumi dan bangunan perdesaan dan perkotaan (PBB-P2) sebagai sumber pendapatan asli daerah kabupaten minahasa, kabupaten minahasa utara, dan kota Manado. Skripsi. Universitas Sam Ratulangi. Manado

Dirjen Perimbangan Keuangan. 2014. Pendoman Umum Pengelolaan Pajak Bumi dan Bangunan Perdesaan dan Perkotaan. Jakarta.

Jusup, Haryono. 2013. Dasar-Dasar Akuntansi. Yogyakarta: STIE YKPN.

Mardiasmo. 2014. Perpajakan. Edisi Revisi. Andi. Yogyakarta

Resmi,Siti. 2013. Perpajakan Teori dan Kasus. Edisi ke empat. Salemba Empat. Jakarta

Riduansyah, Mohammad. 2013. Kontribusi pajak daerah dan retribusi daerah Terhadap pendapatan asli daerah (PAD) dan anggaran Pendapatan dan belanja daerah (APBD) guna mendukung Pelaksanaan Otonomi Daerah (Studi Kasus Pemerintah Daerah Kota Bogor). Makara. Sosial Humaniora. Vol. 7. No. 2. Desember 2003. Pusat Pengembangan dan Penelitian, Fakultas Ilmu Sosial dan Ilmu Politik, Universitas Indonesia, Depok 16425, Indonesia.

Samsul, Bachri. 2010. Pengaruh Pajak Bumi Dan Bangunan Terhadap Pendapatan Asli Daerah Kota Palopo. Skripsi. Universitas Cokroaminoto Palopo. Palopo

Setiawan \& Basri Musri. 2015 perpajakan umum, Edisi 1, PT. Raja Grafindo Persada. Jakarta.

Siburan, Venty Br. 2013. Pelaksanaan Pemungutan Pajak Bumi Dan Bangunan Dalam Meningkatkan Pendapatan Asli Daerah Di Kabupaten Sarolangun. Skripsi. Universitas Jambi. Jambi.

Supriyanto, Edy 2015. Perpajakan di Indonesia. Edisi 1. GRAHA ILMU. Yogyakarta.

Soeprapto, Maria Farida Indrati. 2011. Ilmu Perundang-Undangan. Bandung

Syarifin Pipim dan Jubaedah Dedah. 2015. Hukum Pemerintahan Daerah. Pustaka Bani Quraisy. 
Umar, Muhammed Akilu. 2013. A Thesis Submitted in Partial Fulfillment of the Requirement for the Award of the Degree of Master of Real Estate and Facilities Managemen. Skripsi. Faculty of Technology Management and Business University Tun Hussein Onn Malaysia. Malaysia.

Widari, Berlia Esti. 2016. Analisis Penerimaan Pajak Bumi Dan Bangunan Terhadap Pendapatan Daerah Pemerintah Kota Surabaya. Skripsi. Sekolah Tinggi Ilmu Ekonomi (STIE). Surabaya. 